'Laboratôrio de Patologia de Sementes (LAPAS), Instituto Agronômico de Pernambuco (IPA), Av. General San Martin, 1371, Bongi, CEP 50761-000, Recife, PE, Brasil

${ }^{2}$ Laboratôrio de Pós-colheita, Departamento de Agronomia, Universidade Federal Rural de Pernambuco (UFRPE), Recife, PE, Brasil

*autor correspondente 凶luciana.sartori@ipa.br

\section{Metodologia alternativa no manejo da antracnose pós-colheita em Heliconia rostrata}

\author{
Alternative approach in the management of post-harvest \\ anthracnose in Heliconia rostrata
}

Luciana Melo Sartori Gurgel ${ }^{*}$, Rildo Sartori Barbosa Coêlho ${ }^{1}$, Roberto Luiz Xavier da Silva², Sônia Maria Alves de Oliveira², Regina Ceres Torres da Rosa' ${ }^{1}$, Tereza Cristina de Assis ${ }^{1}$, Domingos

Eduardo Guimarães Tavares Andrade ${ }^{1}$
RESUMO: A Heliconia rostrata pode ser afetada por diversas doenças de importância econômica, destacando-se a antracnose, causada pelo fungo Colletotrichum gloeosporioides, que reduz a produtividade e/ou desvaloriza as flores para comercialização. Este trabalho objetivou estabelecer uma metodologia alternativa de controle da antracnose em cultivares de helicônia e determinar qual o indutor mais eficiente no controle da antracnose em pós-colheita. Os indutores foram aplicados na flor fechada 5 a 7 dias antes e após a emissão da inflorescência, antes da colheita, através da pulverização, utilizando-se duas dosagens: Bion 10 e $20 \mathrm{~g}$ PC/100 L de água; Jasmonato 15 e $30 \mathrm{mg} / \mathrm{L}$ de água; Agro-mos ${ }^{\circledR}$ 100-200 mL/100 L de água; Crop-Set ${ }^{\circledR} 100-200 \mathrm{~mL} / 100 \mathrm{~L}$ de água; Ecolife ${ }^{\circledR 40}$ 100-200 mL/100 L de água. Na avaliação, foram observadas as dimensões das lesões e procedeu-se à análise de peroxidase. As helicônias responderam à aplicação dos indutores com menores níveis de severidade, em todos os tratamentos, com exceção do Bion, em relação à testemunha. Os indutores Ecolife $^{\circledR 40}$ e Jasmonato proporcionaram menor severidade, quando utilizados na menor e maior dose, respectivamente. A maior produção de peroxidase em helicônia foi verificada nas hastes tratadas com Crop-set ${ }^{\circledR}$ e Agro-mos ${ }^{\circledR}$.

PALAVRAS-CHAVE: Indução de resistência, Colletotrichum gloeosporioides, Flores tropicais, Controle alternativo.
ABSTRACT: Heliconia rostrata can be affected by various diseases of economic importance, especially anthracnose caused by Colletotrichum gloeosporioides, which reduces productivity and/ or commercially devalues the flowers. This study aimed to establish an alternative methodology for the control of anthracnose in cultivars of heliconia and determine the most effective inductor in controlling anthracnose in postharvest. Inductors were applied to closed flowers 5-7 days before and after inflorescence emission before harvest. The following inductors were applied by foliar spraying at two strengths: Bion, 10 and $20 \mathrm{~g} L$ PC/100 water; Jasmonate, 15 and $30 \mathrm{mg} / \mathrm{L}$ of water; Agro-mos ${ }^{\circledR}, 100-200 m L / 100$ L water, Crop-Set ${ }^{\circledR}, 100-200 m L / 100$ L water; and Ecolife $^{\circledR 40}, 100-200 \mathrm{~mL} / 100 \mathrm{~L}$ water. The size of lesions and analysis of peroxidase were observed during evaluation. Heliconia responded to the application of inducers, with lower levels of severity, in all treatments except Bion compared to control. The inductors Ecolife ${ }^{\circledR}$ and Jasmonate provided lower severity when used in the lower and higher doses, respectively. The highest yield of peroxidase was observed in heliconia stems treated with Crop-Set ${ }^{\circledR}$ and Agro-mos ${ }^{\circledR}$.

KEYWORDS: Induced resistance, Colletotrichum gloeosporioides, Tropical flowers, Alternative control.

\section{Introdução}

No Nordeste, o setor de produção e comercialização de plantas ornamentais apresentou crescimento contínuo nos últimos anos, promovendo o desenvolvimento da agricultura familiar, com a geração de empregos diretos e o rápido retorno de investimentos, quando comparado a outras atividades agrícolas (GRAZIANO, 2002). 
Entre as flores tropicais, destacam-se as helicônias, nativas dos trópicos do continente americano, entre o México Central e a Região Sul do Brasil, com aproximadamente 180 espécies descritas, dentre as quais Heliconia psittacorum; H. rostrata; H. bihai; H. stricta; H. hirsuta; H. augusta, e H. chartaceae (BRAINER; OLIVEIRA, 2006; WARUMBY; COELHO; LINS, 2004). As condições climáticas de cultivo de helicônia em Pernambuco favorecem a produção de flores com excelente qualidade. Entretanto, as doenças de plantas limitam a produção desta espécie e causam prejuízos diretos, pela redução do valor das flores para comercialização, e indiretos, pelo custo elevado no manejo da cultura (SOLOGUREN; JULIATTI, 2007).

A antracnose, causada pelo fungo Colletotrichum gloeosporioides, provoca danos em folhas e inflorescências de várias espécies de helicônia (WARUMBY; COELHO; LINS, 2004; BARGUIL et al., 2005). Em H. rostrata, os sintomas iniciam-se por pequenos pontos escuros nas brácteas, que vão coalescendo até necrosar toda a inflorescência (COELHO; WARUMBY, 2002). Recentemente, várias medidas de controle têm sido adotadas pelos produtores para manter a alta qualidade das flores e atender às exigências do mercado (SOLOGUREN; JULIATTI, 2007).

$\mathrm{Na}$ natureza, as plantas estão expostas ao ataque de herbívoros e patógenos, e ao longo do processo evolutivo, desenvolveram mecanismos de defesa classificados em pré-existentes ou induzidos. Dentre os primeiros, destacam-se ceras, cutícula, parede celular, tricomas, estômatos e fibras vasculares, bem como substâncias químicas pré-formadas, como fenóis, alcaloides, glicosídeos, fototoxinas e enzimas hidrolíticas. Entre os mecanismos induzidos, destacam-se: formação de papila, lignificação da parede celular, tiloses, produção de fitoalexinas, PR-proteínas e espécies reativas de oxigênio (AGRIOS, 2005; KUNH et al., 2006).

A indução de resistência ocorre pela ativação de mecanismos de defesa das plantas contra patógenos, por meio de indutores bióticos e abióticos. Este método alternativo de controle tem-se destacado pela redução da dependência de produtos químicos e pela possibilidade, em algumas culturas, da utilização de cultivares com alto potencial agrícola e reduzida resistência a determinados patógenos (METRAUX, 2001; BONALDO et al., 2005). Em flores tropicais, a resistência induzida tem sido pouco estudada e, no futuro, pode ser um método eficiente para o controle alternativo da antracnose em H. rostrata.

O presente trabalho teve como objetivo avaliar o efeito de pulverizações com diferentes doses de alguns indutores de resistência no controle da antracnose em $H$. rostrata.

\section{Material e Métodos}

Os experimentos foram conduzidos no Laboratório de Pós-Colheita do Departamento de Agronomia da Universidade Federal Rural de Pernambuco e em plantio comercial em Aldeia-PE.

Brácteas de $H$. rostrata com sintomas de necrose foram coletadas e acondicionadas separadamente em sacos plásticos, e levadas ao laboratório para o isolamento do patógeno.
Fragmentos da região de transição da lesão foram retirados e desinfestados com hipoclorito de sódio $(\mathrm{NaOCl})$ a $1,5 \%$ de cloro ativo, durante 1 a 2 minutos, e, em seguida, lavados por duas vezes em água destilada esterilizada. Os fragmentos foram transferidos para placas de Petri contendo meio de batatadextrose-ágar (BDA) e incubados em condição de laboratório, durante sete dias. Após obtenção do isolado, cultura pura foi preservada a $5^{\circ} \mathrm{C}$ em tubos de ensaios contendo meio BDA, para os estudos subsequentes. Os postulados de Koch foram seguidos para avaliação da patogenicidade do isolado fúngico.

A identificação do patógeno foi realizada com a utilização de primers espécie-específicos, conforme metodologia proposta por Mills et al. (1992).

\section{Extração e quantificação do DNA fúngico}

$\mathrm{O}$ isolado de Colletotrichum foi cultivado em $150 \mathrm{~mL}$ de Batata-Dextrose (BD) à temperatura de $25 \pm 2^{\circ} \mathrm{C}$, sob condição de alternância luminosa (12 horas claro/12 horas escuro), com duas agitações diárias durante seis dias. O DNA do isolado foi extraído a partir de $250 \mathrm{mg}$ de micélio, de acordo com o protocolo descrito por Faleiro et al. (2004) modificado. O DNA foi quantificado visualmente em gel de agarose a $0,8 \%$ e corado em solução de brometo de etídio a $0,05 \mathrm{mg} / \mathrm{L}$, a partir da comparação com um padrão de DNA (Low DNA Mass Ladder, Invitrogen).

A reação em cadeia da polimerase (PCR) foi ajustada para um volume final de $25 \mathrm{~L}$ contendo 10 a $70 \mathrm{ng}$ de DNA genômico, 0,25 M de cada primer (CgInt e ITS4), $200 \mu \mathrm{M}$ de dNTPs, 1,5 mM MgCl $2,1,25 \mathrm{U}$ Taq DNA polymerase e água ultrapura para completar o volume final. A amplificação foi realizada sob as seguintes condições: um ciclo a $95^{\circ} \mathrm{C}$ por 5 minutos, 40 ciclos a $95^{\circ} \mathrm{C}$ por 30 segundos, $65^{\circ} \mathrm{C}$ por 30 segundos, $72^{\circ} \mathrm{C}$ por 1,5 minuto e um ciclo de $72^{\circ} \mathrm{C}$ por 5 minutos. Os produtos da amplificação foram separados em géis de agarose a 1,5\% em tampão Tris-acetato-EDTA. A eletroforese horizontal ocorreu a $80 \mathrm{~V}$ até que a linha de fronte migrasse $5 \mathrm{~cm}$; em seguida, o gel foi corado em solução de brometo de etídio a $0,5 \mathrm{mg} / \mathrm{L}$ para posterior visualização dos produtos sob luz ultravioleta.

\section{Aplicação dos indutores}

Os indutores foram aplicados na flor fechada 5 a 7 dias antes e após a emissão da inflorescência, pulverizando as flores antes da colheita com as seguintes doses de cada indutor: Bion $10 \mathrm{e}$ $20 \mathrm{~g} \mathrm{PC} / 100$ litros de água; Jasmonato 15 e $30 \mathrm{mg} \mathrm{JA} /$ litro de água; Agro-mos ${ }^{\circledR}$ 100-200 mL/100 litros de água; Crop-Set ${ }^{\circledR}$ 100-200 mL/100 litros de água; Ecolife ${ }^{\circledR 40}$ 100-200 mL/100 litros de água. As plantas controle foram pulverizadas com água destilada e esterilizada.

Após a colheita, as hastes foram levadas para laboratório, tratadas com os indutores e inoculadas com Colletotrichum gloeosporioides em duas brácteas, através da deposição de discos de micélio contendo estruturas do patógeno, com ferimento. As mesmas ficaram em câmara úmida por 24 horas. $\mathrm{Na}$ avaliação, foram observadas as dimensões das lesões, a percentagem de controle, considerando-se cada tratamento em relação à testemunha, e a atividade de peroxidase. As plantas 
do tratamento controle foram inoculadas com o patógeno, sem aplicação dos indutores.

O preparo dos extratos enzimáticos consistiu na maceração com nitrogênio líquido de 1,5 g de amostras, $6 \mathrm{~mL}$ de tampão acetato de sódio $20 \mathrm{mM}$, seguida de centrifugação por 5 minutos a $9000 \mathrm{~g} \mathrm{a} 4^{\circ} \mathrm{C}$. Em seguida, o sobrenadante foi transferido para tubos e armazenado a $-80^{\circ} \mathrm{C}$, até o uso do extrato bruto na análise da atividade enzimática.

A atividade da peroxidase foi realizada através da mistura reacional, de $25 \mu \mathrm{L}$ de guaiacol $(0,02 \mathrm{M}), 250 \mu \mathrm{L}$ de peróxido de hidrogênio $(0,38 \mathrm{M})$ e $1,0 \mathrm{~mL}$ de tampão acetato de sódio $(0,2 \mathrm{M} / \mathrm{pH} 5,2)$. A reação foi iniciada com a adição de $25 \mu \mathrm{L}$ do sobrenadante do extrato enzimático, sendo realizadas leituras espectrofotométricas $(470 \mathrm{~nm})$ por três minutos. O cálculo da atividade enzimática foi realizado com base no delta $(\Delta)$ de absorbância, por miligrama de proteínas.

$\mathrm{O}$ delineamento foi inteiramente casualizado, em arranjo fatorial 5 (indutores) $\times 2$ (doses), com cinco repetições por tratamento. Cada repetição foi composta de uma haste com duas brácteas. Os dados foram submetidos à análise de variância e as médias comparadas pelo teste de Duncan a 5\% de probabilidade.

\section{Resultados e Discussão}

A identificação de Colletotrichum gloeosporioides como agente causal da antracnose em brácteas de $H$. rostrata foi confirmada pela obtenção de um fragmento de $450 \mathrm{pb}$ resultante da amplificação com os primers CgInt e ITS4 (MILLS et al., 1992). Essa espécie é o principal agente causal da antracnose em H. rostrata e outras flores tropicais (BARGUIL et al., 2009).

A severidade da antracnose foi reduzida em brácteas de $H$. rostrata pulverizadas com as diferentes doses dos indutores Agro-mos ${ }^{\circledR}$, Crop-Set ${ }^{\circledR}$, Ecolife e Jasmonato (Tabela 1, Figura 1). A atomização de Agro-mos ${ }^{\circledR}$ e Crop-Set ${ }^{\circledR}$ em brácteas de $H$. rostrata reduziu a severidade da antracnose em $20 \%$. Rosa et al. (2007) indicaram o uso dos indutores Agro-mos ${ }^{\circledR} \mathrm{e}$ Crop-Set $^{\circledR}$, em mistura, no manejo do míldio da videira, uma vez que os mesmos reduziram a severidade da doença em até $37,46 \%$, o que equivale a uma percentagem de controle de $29,01 \%$.

A) Menor dose

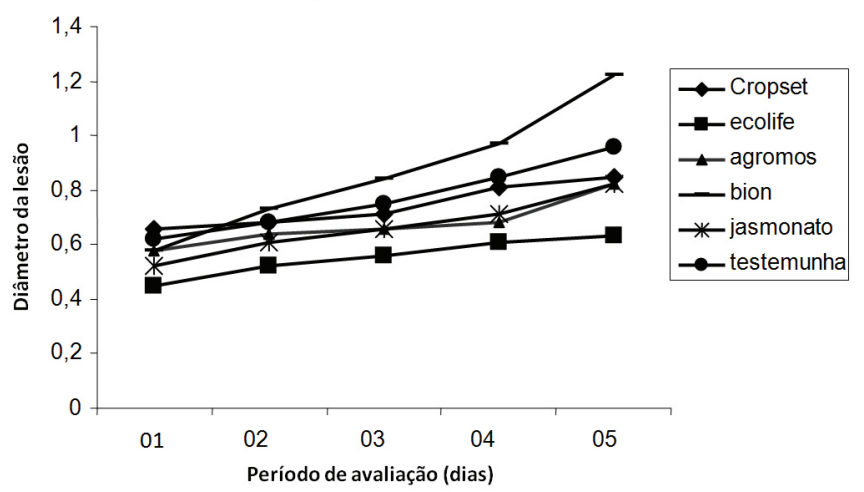

$\mathrm{Na}$ avaliação da eficiência dos produtos, a melhor indução de resistência na helicônia à antracnose ocorreu quando foi aplicado Ecolife na menor dose e Jasmonato na maior dose, diferindo significativamente da testemunha e de Bion, mas não dos demais indutores. Estes produtos promoveram controle de $40 \%$ e $38,09 \%$ da doença, respectivamente, podendo ser utilizados no manejo da antracnose em $H$. rostrata. Furtado et al. (2010) verificaram a eficácia do Ecolife no controle da antracnose da banana em pós-colheita, em que observaram tamanhos de lesões significativamente menores em relação à testemunha, quando esse indutor foi aplicado. Cruz et al. (2011) verificaram uma redução significativa na severidade da murcha de fusário do tomateiro quando o Ecolife foi pulverizado 5 e 10 dias antes da inoculação. Esses autores também avaliaram o efeito direto dos indutores Bion, Ecolife, Biopirol e Óleo de Nim sobre o Fusarium oxysporum f.sp. lycopercisi, em que o Ecolife foi considerado o melhor tratamento, inibindo significativamente o crescimento micelial do fungo. Vários trabalhos demonstram a natureza indutora do Ecolife pela produção de fitoalexinas envolvidas na expressão da resistência a fitopatógenos (CRUZ et al., 2011; KEEN, 1990).

Avaliando-se o progresso da antracnose e considerando as avaliações de sintomas externos, observa-se, de modo geral, que as plantas responderam à aplicação dos indutores, com menores níveis de severidade em todos os tratamentos - com exceção do Bion - em relação à testemunha. Resultados similares foram obtidos por Oliveira e Coelho (2005), em que três aplicações de Bion em Heliconia psittacorum cv. Golden Torch não foram eficientes para o controle da antracnose nas folhas. Querino et al. (2005) também não constataram redução da severidade do mal-do-panamá em plantas micropropagadas de banana-maçã e Grande Naine, quando tratadas com Bion utilizando-se cinco dosagens, em condições de casa de vegetação. Resultados similares foram observados por Moura et al. (2012), utilizando diferentes indutores de resistência para o controle de podridões pós-colheita em frutos de manga, em que verificaram uma incidência de podridão em $77,9 \%$ dos frutos tratados. Resultado contrário foi obtido por Dantas et al. (2004), que observaram redução em torno de $70 \%$

B) Maior dose

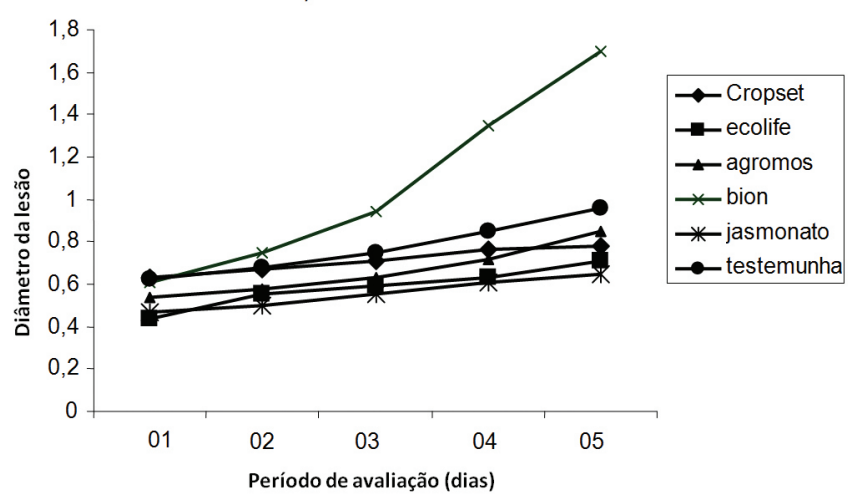

Figura 1. Progresso dos sintomas da antracnose em brácteas de Heliconia rostrata, em resposta à aplicação com diferentes indutores de resistência. 
Tabela 1. Severidade da antracnose em inflorescências de Helicônia rostrata pulverizadas com duas doses de indutores de resistência.

\begin{tabular}{|c|c|c|c|}
\hline \multirow{2}{*}{ Indutor } & \multirow{2}{*}{ Dose } & \multicolumn{2}{|c|}{ Sintomas Externos $^{1}$} \\
\hline & & Diâmetro lesão & Percentagem de controle \\
\hline \multicolumn{4}{|c|}{ D1 } \\
\hline Bion & $10 \mathrm{~g} / 100 \mathrm{~L}$ & $1,22 \mathrm{c}$ & 0,00 \\
\hline Testemunha & - & $1,05 \mathrm{bc}$ & - \\
\hline Jasmonato & $15 \mathrm{mg} / \mathrm{L}$ de água & $0,82 \mathrm{ab}$ & 21,90 \\
\hline Agro-mos ${ }^{\circledR}$ & $100 \mathrm{~mL} / 100 \mathrm{~L}$ de água & $0,81 \mathrm{ab}$ & 22,85 \\
\hline Crop-Set ${ }^{\circledR}$ & 100 mL/100 L de água & $0,85 \mathrm{ab}$ & 19,04 \\
\hline Ecolife & 100 mL/100 L de água & $0,63 \mathrm{a}$ & 40,00 \\
\hline \multicolumn{4}{|c|}{ D2 } \\
\hline Bion & $20 \mathrm{~g} / 100 \mathrm{~L}$ & $1,70 \mathrm{c}$ & 0,00 \\
\hline Testemunha & - & $1,05 \mathrm{~b}$ & - \\
\hline Jasmonato & 30 mg/L de água & $0,65 \mathrm{a}$ & 38,09 \\
\hline Agro-mos $^{\circledR}$ & 200 mL/100 L de água & $0,85 \mathrm{ab}$ & 19,04 \\
\hline Crop-Set $^{\circledR}$ & 200 mL/100 L de água & $0,78 \mathrm{ab}$ & 25,71 \\
\hline Ecolife & 200 mL/100 L de água & $0,71 \mathrm{ab}$ & 32,38 \\
\hline CV (\%) 20,78 & & & \\
\hline
\end{tabular}

${ }^{1}$ Médias seguidas da mesma letra na coluna não diferem estatisticamente entre si, pelo teste de Ducan a 5\% de probabilidade.

Tabela 2. Atividade de peroxidase em inflorescências de Heliconia rostrata pulverizadas com diferentes indutores de resistência e inoculadas com Colletotrichum gloeosporioides.

\begin{tabular}{|c|c|c|}
\hline \multirow{2}{*}{ Indutor } & \multirow{2}{*}{ Dose $\left(\mathrm{mgL}^{-1}\right)$} & Peroxidase $^{1}$ \\
\hline & & $\Delta$ absorbância $_{470}$ por minuto por grama \\
\hline \multicolumn{3}{|c|}{ D1 } \\
\hline Bion & $10 \mathrm{~g} / 100 \mathrm{~L}$ & $19,57 \mathrm{~b}$ \\
\hline Testemunha & - & $16,69 \mathrm{~b}$ \\
\hline Jasmonato & 15 mg/L de água & $2,72 \mathrm{c}$ \\
\hline Agro-mos ${ }^{\circledR}$ & 100 mL/100 L de água & $4,40 \mathrm{c}$ \\
\hline Crop-Set ${ }^{\circledR}$ & 100 mL/100 L de água & 30,42 a \\
\hline Ecolife & 100 mL/100 L de água & $16,72 \mathrm{~b}$ \\
\hline \multicolumn{3}{|c|}{ D2 } \\
\hline Bion & $20 \mathrm{~g} / 100 \mathrm{~L}$ & $5,76 \mathrm{c}$ \\
\hline Testemunha & - & $16,69 \mathrm{~b}$ \\
\hline Jasmonato & $30 \mathrm{mg} / \mathrm{L}$ de água & $8,32 \mathrm{c}$ \\
\hline Agro-mos $^{\circledR}$ & 200 mL/100 L de água & 21,68 a \\
\hline Crop-Set $^{\circledR}$ & 200 mL/100 L de água & $14,60 \mathrm{~b}$ \\
\hline Ecolife & 200 mL/100 L de água & $15,28 \mathrm{~b}$ \\
\hline CV (\%) 34,21 & & \\
\hline
\end{tabular}

${ }^{1}$ Médias seguidas da mesma letra na coluna não diferem estatisticamente entre si, pelo teste de Ducan a 5\% de probabilidade.

da antracnose em mamões tratados com Bion e Agro-Mos ${ }^{\circledR}$ na pré-colheita, e $80 \%$ nos tratamentos pré + pós-colheita.

As peroxidases são glicoproteínas, responsáveis pela formação de lignina através da polimerização de fenóis; portanto, o aumento da sua atiividade indica a ativação de mecanismos de defesa das plantas contra o ataque de patógenos
(VAN LOON; REP; PIETERSE, 2006; BOAVA et al., 2010). Embora a menor severidade da antracnose ter sido observada nas brácteas pulverizadas com Ecolife e Jasmonato, a maior atividade da peroxidase ocorreu nas hastes tratadas com Crop-Set ${ }^{\circledR}$ e Agro-mos ${ }^{\circledR}$ (Tabela 2). Resultados similares foram obtidos com a aplicação de Agro-mos ${ }^{\circledR}$ para o 
controle pós-colheita da antracnose em maracujá-amarelo (LIMA FILHO, 2008). A atividade de peroxidase na testemunha indica que a infecção de $C$. gloeosporioides ativou mecanismos de defesa da planta.

\section{Conclusões}

Os indutores de resistência Jasmonato, Agro-mos, Crop-Set e Ecolife são importantes ferramentas a serem utilizadas no manejo da doença, reduzindo a quantidade de fungicida utilizada no controle da antracnose em $H$. rostrata.

\section{Referências}

AGRIOS, G. N. Plant Pathology. 5th ed. Amsterdan: Elsevier Academic Press, 2005. 922 p.

BARGUIL, B. M. et al. Ocorrência de Colletotrichum gloeosporioides em Heliconia chartacea cv. Sex Pink. Fitopatologia Brasileira, Brasília, v. 30, p. 136, 2005. http://dx.doi.org/10.1590/S010384782009005000126

BARGUIL, B. M. et al. Identificação e variabilidade genética de isolados de Colletotrichum causando antracnose em inflorescências de plantas ornamentais tropicais. Ciência Rural, Santa Maria, v. 39, n. 6, p. 1639-1646, 2009.

BOAVA, L. P. et al. Efeito de indutores bióticos e abióticos na atividade de quitinase e peroxidase e no controle da ferrugem causada por Puccinia psidii em eucalipto. Summa Phytopathologica, Botucatu, v. 36, n. 2, p. 168-172, 2010. http://dx.doi.org/10.1590/ S0100-54052010000200012

BONALDO, M. B. et al. Indução de resistência: noções básicas e perspectivas. In: CAVALCANTI, L. S. et al. (Eds.). Indução de resistência em plantas a patógenos e insetos. Piracicaba: FEALQ, 2005. p. 11-28.

BRAINER, M. S. C. P.; OLIVEIRA, A. A. P. Perfil da floricultura no Nordeste Brasileiro. In: CONGRESSO DA SOBER, 44., 2006, Fortaleza. Anais... Foraleza: BNB, 2006. 1 CD-ROM.

COELHO, R. S. B.; WARUMBY, J. F. Doenças de plantas ornamentais tropicais detectadas na Zona da Mata de Pernambuco. Floricultura em Pernambuco, Série Agronegócio, Sebrae-PE. v. 1, p. $67-$ 69, 2002.

CRUZ, S. M. C. et al. Ação indutora de produtos abióticos na resistência de tomateiro e efeito sobre o crescimento micelial de Fusarium oxysporum f.sp. lycopersici. Idesia, Arica, v. 29, n. 2, p. 111-118, 2011. http://dx.doi.org/10.4067/S071834292011000200015

DANTAS, S. A. F. et al. Indutores de resistência na proteção do mamão contra podridões pós-colheita. Summa Phytopathologica, Botucatu, v. 30, n. 3, p. 314-319, 2004.

FALEIRO, F. G. et al. Caracterização e diversidade genética de isolados de Phytophthora spp. do cacaueiro com base em marcadores RAPD. Fitopatologia Brasileira, Brasília, v. 29, p. 303-30, 2004. http:// dx.doi.org/10.1590/S0100-41582004000300011
FURTADO, L. M. et al. Utiliização de Ecolife e Acibenzolar-s-metil (ASM) no controle da antracnose da banana em pós-colheita. Summa Phytopathologica, Botucatu, v. 36, n. 3, p. 237-239, 2010.

GRAZIANO, T. T. (Coord.). Relatório do Diagnóstico da produção de flores e plantas ornamentais brasileira. 2002. Relatório Ibraflor/Apex. Mimeografado.

KEEN, N. T. Phytoalexins and their elicitors. In: HOAGLAND, R. E. Microbes and microbial products as herbicides. Washington: American Chemical Society, 1990. p. 114-129. http://dx.doi. org/10.1021/bk-1990-0439.ch006

KUNH, J. O. et al. Indução de Resistência sistêmica em plantas: aspectos gerais, efeitos na produção e sobre microrganismos não-alvo. Revisão Anual de Patologia de Plantas, Passo Fundo, v. 14, p. 251-302, 2006

LIMA FILHO, R. M. Controle alternativo da antracnose no maracujá-amarelo na pós-colheita. 2008. 75 f. Tese (Doutorado)Universidade Federal Rural de Pernambuco, Recife, 2008.

QUERINO, C. M. B. et al. Efeito de dois indutores de resistência sobre a severidade do Mal-do-Panamá. Fitopatologia Brasileira, Brasília, v. 30, n. 3, p. 239-243, 2005. http://dx.doi.org/10.1590/ S0100-41582005000300004

METRAUX, J. P. Systemic acquired resistance and salicylic acid: current state of knowledge. European Journal of Plant Pathology, Dordrecht, v. 107, p. 6-13, 2001.

MILLS, P. R.; SREENIVASAPRASAD, S.; BROWN, A. E. Detection and differentiation of Colletotrichum gloeosporioides isolates using PCR. FEMS Microbiology Letters, Amsterdam, v. 77, p. 137-143, 1992. PMid:1459401. http://dx.doi org/10.1111/j.1574-6968.1992.tb05503.x

MOURA, M. D. C. S. et al. Potencial de produtos bióticos e abióticos como indutores de resistência no controle de podridões pós-colheita em manga, no submédio São Francisco. Revista Caatinga, Mossoró, v. 25, p. 44-49, 2012.

OLIVEIRA, A. C. C.; COELHO, R. S. B. Eficiência de fungicidas e indutor de resistência no controle da antracnose (Colletotrichum gloeosporioides) em Heliconia psittacorum cv. Golden Torch. Summa Phytopathologica, Botucatu, v. 31, n. 1, p. 94-96, 2005.

ROSA, R. C. T. et al. Efeito de indutores no controle de míldio em Vitis labrusca. Summa Phytopathologica, Botucatu, v. 33, n. 1, p. 68 73, 2007. http://dx.doi.org/10.1590/S0100-54052007000100010

SOLOGUREN, F. J.; JULIATTI, F. C. Doenças fúngicas em plantas ornamentais em Uberlândia-MG. Bioscience Journal, Uberlândia, v. 23, n. 2, p. 45-52, 2007.

VAN LOON, L. C.; REP, M.; PIETERSE, C. M. J. Significance of inducible defense-related proteins in infected plants. Annual Review of Phytopathology, Palo Alto, v. 44, p. 135 162, 2006. Pmid:16602946. http://dx.doi.org/10.1146/annurev. phyto.44.070505.143425

WARUMBY, J. F.; COELHO, R. S. B.; LINS, S. R. O. Principais doenças e pragas em flores tropicais no estado de Pernambuco. Recife: Sebrae, 2004. 98 p. 